\title{
Shell repair process in the green ormer Haliotis tuberculata: A histological and microstructural study
}

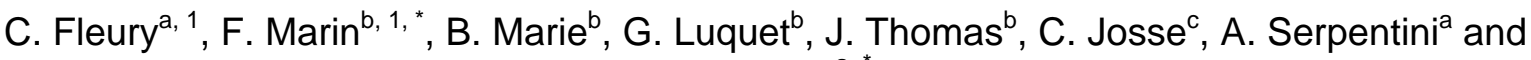 \\ J.M. Lebel ${ }^{a, *}$
}

\begin{abstract}
a Laboratoire de Physiologie et Ecophysiologie des Mollusques Marins, UMR 100 IFREMER, IFR 146 ICORE, Université de Caen Basse Normandie, Esplanade de la Paix, 14032 CAEN Cedex, France

b Laboratoire de Biogéosciences, UMR CNRS 5561, Université de Bourgogne, 6 Boulevard Gabriel, 21000 Dijon, France

c Laboratoire de Réactivité des Solides, Bâtiment Mirande, Université de Bourgogne, BP 47870, 21078 Dijon Cedex, France

${ }^{1}$ These authors contributed equally to this work.

*: Corresponding author : F. Marin, email address : frederic.marin@u-bourgogne.fr, J. M. Lebel, email address : jean-marc.lebel@unicaen.fr
\end{abstract}

\begin{abstract}
:
In the present paper, juvenile and adult shells of the green ormer Haliotis tuberculata ('Oreille de Saint-Pierre') were perforated in a zone close to the shell edge and the shell repair process was followed at two levels: (1) by observing the histology of the calcifying mantle in the repair zone and (2) by analyzing with SEM the microstructure of the shell repair zone. Histological data clearly show the presence of calcium carbonate granules into the connective tissues, but not in the epithelial cells. This suggests that calcium carbonate granules are synthesized by sub-epithelial cells and actively transported through the epithelium to the repair zone, via a process which may be similar to that described by Mount et al. [Mount, A.S., Wheeler, A.P., Paradkar, R.P., Snider, D., 2004. Hemocytemediated shell mineralization in the eastern oyster. Science 304, 297-300]. Furthermore, SEM observations show that the repair zone exhibits different stratified microstructures (spherulitic, thin prismatic, blocklike, sub-nacreous, nacreous, foliated-like), some of which are not continuous (i.e. lenticular) along the repair zone. This suggests a complex secreting regime of the calcifying mantle and an elaborate geometry of the epithelium involved in shell repair.
\end{abstract}

Keywords: Gastropod; Shell repair; Calcium carbonate; Biomineralization; Mantle epithelium; Microstructure 


\section{Introduction}

In the metazoan world, the phylum Mollusca represents without contest a remarkable evolutionary success, by the number of living species -120000 and more - by the durability of its constitutive taxa over the different geological periods, and by the extreme adaptability of representatives to different environments. A part of this enduring success relies on a specific organ, the shell, and on the way by which this mineralized exoskeleton is produced. The molluscan shell represents indeed the best example of a solid calcium carbonate biomineralization resulting from the secreting activity of a thin polarized epithelium (Simkiss \& Wilbur, 1989). During calcification periods, this epithelium releases an extracellular organic matrix, which has the remarkable ability to control, over different scales, several aspects of the shell mineralization process (Addadi et al., 2006). It can select the calcium carbonate polymorph used (calcite versus aragonite); it can finely regulate the shapes of the crystallites, a process from which emerge different shell textures: nacreous, prismatic, foliated, crossed lamellar, homogeneous, granular.

One aspect that made the molluscan shell biomineralization so successful lies also in the ability of molluscs to rapidly repair shell damages, an undeniable evolutionary advantage for overcoming all kinds of external aggressions: accidental physical shell cracks, shell boring by epibiont organisms (sponges, for example), or active predation by fishes. Although the shell is a 'dead' non-cellular tissue, it exhibits certain plasticity, and the ability of molluscs to slightly 'remodel' their shell - in particular in case of calcium ion deprivation - is known in a number of cases (Wagge 1951; Chan and Saleuddin, 1974). When this happens, molluscs can re-dissolve the most recently synthesized crystallites, and calcium is re-absorbed by the epithelial tissues. This takes place for instance during anaerobic phases.

The shell repair processes have been studied in numerous cases, including marine gastropods (Muzii and Skinner, 1966), freshwater gastropods (Davis, 1964; Meenakshi et al., 1975; Blackwelder and Watabe, 1977), land snails (Andrews, 1934; Abolins-Krogis, 1958, 1963a, b, 1976, 1979; Saleuddin, 1970; Kapur and Sen Gupta, 1970; Ganagarajah and Saleuddin, 1972; Chan and Saleuddin, 1974), bivalves (Loosanoff and Nomejko, 1955; Beedham, 1965; Meenakshi et al., 1973; Tsujii, 1976; Mount et al., 2004) and cephalopods (Meenakshi et al., 1974). Basically, the shell regeneration process was analyzed following different procedures: physical shell lesion, including shell cracking (Andrews, 1934), shell cutting (Caseiro and Gauthier, 1997) and shell drilling (Kapur and Gupta, 1970; Caseiro and Gauthier, 1998), or insertion of a foreign body/substrate between the calcifying mantle and the shell (Kapur and Gupta, 1970; Zaremba et al., 1996). In some cases, the shell repair process was analyzed following infestation by boring organisms (Marshall and Day, 2001; Nollens et al., 2002; Huchette et al., 2006)

Most of these studies analyzed very precisely the physiology and histology of mantle during shell repair. Only few works characterized shell repair at the microstructural level (Caseiro and Gauthier, 1997, 1998; Marshall and Day, 2001). In the present study, we combine both approaches by describing on one side the histology of the mantle at the repair zone and by looking at the microstructure of the repaired shell, on the other side. The studied model is the green ormer Haliotis tuberculata, also called abalone or 'Oreille de Saint-Pierre', a common archeogastropod of the French Atlantic coast, and a mollusc of economical interest. The shell of this species exhibits the 'classical' thick nacreous internal layer (Lin and Meyer, 2005), laying on an external layer, which - although most often composed of calcitic prisms - can exhibit important textural variations: spherulites, aggregates (Mutvei et al., 1985; Dauphin et al., 1989; Zaremba et al., 1996). In our study, we perform shell perforation in order to observe on one hand, the presence of $\mathrm{CaCO} 3$ in the mantle of $H$. tuberculata during the shell repair process by histological methods and on the other hand, the microstructure of the repaired shell by SEM.

\section{Material and techniques}

\subsection{Sample collection and shell perforations}

Experiments were conducted on two batches of the abalone Haliotis tuberculata, during winter (January-February): 11 adult specimens (size about $100 \mathrm{~mm}$ ) and 40 juveniles (size about $35 \mathrm{~mm}$ ). Living adult specimens were fished in the area of Cherbourg (Normandy, France), whereas juveniles 
ones were collected in an abalone hatchery (Les Ormeaux du Cotentin, Gouville sur Mer, Normandy). Specimens were kept in seawater at $18^{\circ} \mathrm{C}$ at the Centre de Recherche en Environnement Côtier (Luc sur Mer, Normandy) and regularly fed with a mixture of Laminaria sp. and Palmaria palmata.

For adults, a hand drill was used to perform perforations of $7 \mathrm{~mm}$ diameter at 0.5 to $1 \mathrm{~cm}$ from the shell edge, whereas for juveniles, drills of $2 \mathrm{~mm}$ diameter were performed using a portable power drill, at $2 \mathrm{~mm}$ from the shell border. We took care not to damage the underlying epithelium. Animals were scrupulously cleaned with seawater to remove shell debris, before being put back in the aquarium.

\subsection{Staining and histology of the mantle}

In total, 11 adult specimens were sacrificed: 3 animals, at the moment of experimentation, represented the basal activity of the calcifying epithelium and the 8 others animals were sacrificed after $7,14,30$ and 60 days ( 2 each time). For each specimen, the mantle tissues were immediately fixed for 48 hours with a solution of salt formaldehyde (37\% formaldehyde diluted 10 times in sterile sea water). Then, samples were dehydrated in successive ethanol bathes $(70 \%, 90 \%$ and $100 \% \mathrm{vol} / \mathrm{vol}$ ethanol, 48 hours each bath). The dehydration was completed, by incubating the preparations in a butanol bath for 168 hours.

Samples were paraffin embedded and sliced with a microtome $(3 \mu \mathrm{m}$ thick). The slices were heatglued on glass plates and re-hydrated with successive aqueous ethanol bathes (90 and 70\%). Tissues were stained with Masson's trichrome staining (Gabe, 1968).

In order to visualize concentrations of calcium carbonate, Von Kossa staining (Gabe, 1968) was performed according to the standard procedure with the following modifications: 20 minutes incubation in $5 \%$ (w/vol) silver nitrate in the dark, 3 washes with distilled water for removing the excess of silver nitrate, staining with $0.5 \%$ (w/vol) hydroquinone for 2 minutes in the day light, 3 washes with distilled water, incubation with sodium thiosulfate $(5 \% \mathrm{w} / \mathrm{vol})$ for one minute, 3 washes with distilled water. Samples were dehydrated and mounted with a hydrophobic resin (Roti-histokitt - Roth $\AA$ ) between glass and cover glass.

\subsection{Observations with optical microscope and SEM}

Shell samples were cut with a diamond saw and the repair zone (patch) was further cut from the shell apex to the edge (radial section) in two equal parallel bands. The cut bands were cleaned with water, and dried. For each specimen, one repair band was carbon sputtered and directly observed without surface treatment. The other was embedded in epoxy resin obtained by mixing Araldite glue and its hardener (Brot Technologie). The section surface was treated as follows: polishing with abrasive paste (decreasing granulometry), and finishing (mirror polish) with alumina powder (50 nm Buehler micropolish). Samples were sonicated to remove polishing grains. Sample surfaces were slightly etched with EDTA 1\% (w/vol), pH 7.5 for 3 minutes and sonicated at the same time, before being carefully rinsed with distilled water, and dried at $40^{\circ} \mathrm{C}$. Samples were observed with a Nikon binocular (magnification 5.4 to 40). They were subsequently carbon sputtered and observed with a JEOL JSM 6400F Scanning Electron Microscope under a 10-15 KeV beam.

\section{Results}

\subsection{Observations with optical microscope}

In all subsequent descriptions, we define the proximal zone as the repair area between the shell apex and the mid-perforation. The distal zone corresponds to the repair area comprised between the midperforation and the shell outer edge.

A few hours after the shell lesion, all tested samples reacted in a similar manner: in the perforation zone, the mantle directly beneath the shell hole withdrew towards the shell apex, while it remained in place in the non-damaged zones. As a consequence of this, a "gulf" was formed by the mantle tissues around the hole, a phenomenon characterized by the intimate contact between the mantle edge and the proximal border of the hole. We interpret this as a physiological sealing mechanism for isolating the extrapallial space from seawater. 
For all the considered specimens, the shell repair proceeds from the shell apex to the border (i.e., proximal to distal), and results in the formation of an organo-mineral patch. The early visible step is characterized by the secretion of a brownish organic lamella, which resembles the periostracal layer (Fig. 1A). In internal view, the 'bay' that defines the limit of the organic layer is well marked (Fig. 1A), in particular after 7-15 days. After 15 days, the surface of the hole is one-third to two-thirds covered by the brown membrane patch. In later stages of shell repair (one month), the organic layer appears to mineralize on the internal side in contact with the mantle. The mineralized layer at the repair zone is white and mate, in every case, less iridescent than the surrounding non-repaired nacre.

For some adult specimens that have fully repaired the damaged zone (after 2 months), we observe in the distal part of the patch the deposition of brownish material that can be clearly visualized in external view (Fig. 1B, right). This brown deposit exhibits a concentric striation, which is not in continuity with the growth lines of the surrounding shell. The centre of this striation is the most distal part of the hole, which suggests that the deposit progresses from the shell edge to the apex (Fig. 1B, right). In section, this accumulation exhibits a white aspect (only the top is brown) and is clearly mineralized (Fig. 1C, 2month samples, middle and right). This peculiar deposit is always associated with an upward bulge repair patch. Because a geometrical analogy can be made between this mineralization - 'stuck' between the distal border of the lesion and the subjacent repair mineralization - and the sedimentary accretionary prisms, at the contact of two colliding plates in subduction zones (Allaby and Allaby, 2003), we choose to call this calcified deposit "accretionary mineralization". By no means, we see a similarity in the two mechanisms of formation. We suggest that the accretionary mineralization may indeed correspond to a rapid filling-up secreted by the protruding mantle tissue.

Note that for few samples, we observed the absence of mineralized layer, even after two months. In these cases, the brownish lamella covers the internal surface of the shell far beyond the damaged zone.

\subsection{Histology of the mantle}

The results of the histological staining are shown on Fig. 2. Note that the connective tissues contain numerous cell types, as shown by the trichrome staining (Fig. 2A). In all the tested samples, a positive Von Kossa staining was observed (Fig. 2B to $\mathrm{H}$ ). This contrasts with the observations of Richardson and co-workers (1981) who do not observe any staining in the epithelial cells of Mytilus edulis.

Considering the T0 samples (Fig. 2B and C), Von Kossa reaction gave a faint staining, in particular, in epithelial cells of the outer epithelium. This staining can be considered as the basal calcifying activity of an abalone at this period of the year. The connective tissues of the mantle are not stained at this stage.

At $4,7,15$ and 30 days after shell damage, we observe an intense staining of the connective tissues, localized at the level of granules, the size of which varies from 3 to 5 microns (Fig. $2 \mathrm{C}$ to $\mathrm{H}$ and Fig. 3). This demonstrates that these granules are made of calcium carbonate. The vesicles display a rounded shape with a heterogeneous staining (fig $3 \mathrm{~A}$ to $\mathrm{C}$ ). We note the presence of one Von Kossa positive granule into a hemolymphatic twist (fig $3 \mathrm{~A}$, see arrow) whereas the majority of the granules are located into the connective tissue, beneath the outer epithelium in contact with lesion. Their distribution in the connective tissues is characteristic: they are especially concentrated in a zone directly in contact with the outer epithelial cells, at 150-200 $\mu \mathrm{m}$ under the epithelial cells and between 200 and $400 \mu \mathrm{m}$ from the tip of the outer fold. This zone correspond to the connective underlying epithelial cells involved in the mineral deposition: deposition of calcitic prisms, due to cells at the vicinity of the outer fold tip, deposition of nacre tablets, corresponding to more distally-located cells (Sud et al., 2002 ; Takeuchi and Endo, 2006). However, in this latter case, only a short portion of the 'nacre cells' - the closest to 'prisms cells' - is concerned. The epithelial cells of the outer epithelium are stained similarly to T0, i.e., the staining occurs more or less homogeneously. In opposition to the connective tissues, we do not observe stained granules in these cells.

\subsection{SEM observations}

Plates 4 and 5 show SEM observations of shell repair in two representative adult specimens, after one and two months, respectively. These two plates represent two cases of shell repair: in the first case (plate 4, one month), the repair patch corresponds to a "standard" repair, in term of geometry: the patch is flat and is characterized by the superimposition of one organic and one mineralized layer. After one month, the repaired patch is still thin $(90-100 \mu \mathrm{m})$, the organic layer representing more than 
one third of the total thickness. The superimposed mineral patch is extremely stratified, and not less than four microstructural types can be observed. The interface between the original nacre and the repair patch is underlined by an extremely thin mineral layer (thickness about $5 \mu \mathrm{m}$, plate 4 , photos B, $\mathrm{C}$ and $\mathrm{E}$ ), which is 'vertically-segmented'. Although continuous in the proximal zone, this layer disappears in the distal zone. This layer exhibits morphological resemblance with the blocklike layer, described in the red abalone Haliotis rufescens by Zaremba and co-workers (1996) and by Su et al. (2002). This layer would also be similar to the pigmented layer observed by Marshall and Day (2001) and by Marshall (pers. com.) in the Australian black lip abalone Haliotis rubra. In the absence of a more detailed characterization, and because we did not notice any pigmentation associated with it, we call this microstructure blocklike layer.

In the proximal repair zone (left side of Fig. 4A, point B), the organic layer is directly deposited on the blocklike layer (Plate 4, photos B, C, E), and thickens towards the lesion, until reaching a thickness of above $50 \mu \mathrm{m}$. Towards the lesion, the nacreous layer superimposes to the organic one (Fig. 4C, C', D). This nacre has all the characteristics of columnar nacre, i.e., the tablets are aligned according to the $c$ axis. By progressing towards the distal zone, we observe variations within structure of the patch: appearance of a spherulitic thin layer subjacent to the organic layer (Fig. 4F, G), appearance of discontinuous intermediary layers such as 'sub-nacreous' layers, formation of foliated-like layers. 'Subnacreous' structures, visible in Fig. $4 \mathrm{G}, \mathrm{H}, \mathrm{H}$ ', are localized in particular to the distal half of the lesion. We define as 'sub-nacreous'texture, a microstructure formed from nacre tablets, which do not exhibit a supra-crystalline organization in regular columns. Furthermore, this microstructure appears always blurred, a fact which suggests that this layer is enriched in organic matrix (Fig. 4G, $2^{\text {nd }}$ layer from the bottom). As suggested in earlier work (Gabriel, 1981), a higher protein content of this layer would improve the resistance to boring while the mechanical resistance would be kept reasonably high. The foliated-like layer is lenticular. The G-H zone represents the zone where it becomes thinner (photos $4 G, H$ ), before disappearing, on the right side of point $H$. The foliations of this layer, visible on Fig. 4G (middle), are thicker than nacre tablets, and look continuous on the horizontal plan. In the G-H areas, the underlying 'true'nacre layer is thinner (about $12 \mu \mathrm{m}$ ) than in the proximal zone. In the most distal zone, close to the shell edge, the patch thickness decreases progressively. The neo-formed nacre layer is directly superimposed on a thin layer $(<10 \mu \mathrm{m})$ of minute prism-like crystals (Fig. $4 \mathrm{I})$, which is itself separated from the old nacre by a $10 \mu \mathrm{m}$-thick organic layer.

The second case (Plate 5) corresponds to a more complete (2 months) and geometrically more complex shell repair. The thickness of the patch reaches $700 \mu \mathrm{m}$. The patch exhibits an upward bulge, and a particular mineralization, stuck between the distal border of the perforation and the patch itself. This mineralization is clearly visible on photo $5 \mathrm{~A}$, zone $\mathrm{F}$. We suggest that this mineralization occurs when the mantle tissues push upward and tend to bend the repair patch.

As for plate 4, the thin blocklike layer is visible on the proximal side of the repair (Fig. 5B, C). In this zone, an intermediate mineralization develops onto the blocklike layer: this intermediary zone comprises: a prismatic-like thin layer of variable thickness (up to $4 \mu \mathrm{m}$ ), a nacreous to sub-nacreous layer $(20 \mu \mathrm{m})$, then a true nacre. An organic layer separates the sub-nacre and the nacre. On the proximal side of the hole (Fig. 5D, 5D'), the intermediate layer that separates the original nacre from the patch nacre appears highly stratified and comprises an intimate association of organic and mineralized layers. In the same area, at higher magnification, the contact between the organic matrix and the spherulitic layer (7-8 $\mu \mathrm{m}$ thick) and the subjacent neo-formed nacre is visible (Fig. 5D'). Between points $D$ and $E$, the patch is essentially composed of columnar nacre developed from a finely prismatic layer (Fig. 5E). As described macroscopically, a white organo-mineral accumulation is present, entrapped between the top of the patch and the distal border of the hole. The microstructure of this infilling is porous and made of aggregates of spherulites, of diameter around 15 microns (Fig. $\left.5 F, F^{\prime}, F^{\prime \prime}\right)$. The transition between the spherulites and the nacre is direct, without intervening organic layer (Fig. 5F"), and it is to note that the diameter of spherulites and nacre tablets are similar. The repair zone comprised between the hole and the shell edge (Fig. 5G to 5I) exhibits a complex stratified pattern. For example, in Fig. 5G, one observes successively, from top to bottom, the organic layer, a prismatic layer $(50 \mu \mathrm{m})$, a sub-nacreous layer (about $30 \mu \mathrm{m})$, again a prismatic layer $(15 \mu \mathrm{m})$, a true nacreous layer (about $60 \mu \mathrm{m}$ ), and finally, a thin blocklike layer $(5 \mu \mathrm{m})$. Close to the shell edge, the nacre and sub-nacre layers progressively decrease in thickness, whereas the thickness of prismatic layer remains more or less constant (Fig. $5 \mathrm{H}$ ). The transition between the nacre layer and the thin prismatic layer is achieved only by the disappearance of the vertical partitioning of nacre tablets (Fig. $5 G^{\prime \prime}$ ). At last, at the most distal border of the patch (Fig. 5I), the single mineralized layer that remains is the one constituted of thin prisms, which covers the organic layer. This latter embeds the last formed nacre tablets, the growth of which has been stopped abruptly by the stress induced by the perforation (Fig. 5l). 


\section{Discussion}

\subsection{Kinetics of shell repair}

This paper presents histological and microstructural data obtained from shell lesion on the green ormer Haliotis tuberculata. It calls for few remarks about the kinetics of shell repair, about the presence of calcified granules, and about the microstructural complexity of the repaired zone.

Just few hours after shell injury, the retraction and positioning of the mantle around the shell defect is in agreement with the observations of Beedham (1965) on the damaged shell of Anodonta. Although the formation of a brown non-mineralized layer - described by all the authors in particular by Uozumi and Suzuki (1979) - represents the first step of the repair process, the rapidity with which this layer forms differs according to the considered species and to the habitat. To avoid rapid dessication, the process has to be fast in land snails like Helix pomatia, for which the first organic layer appears one hour after shell damage and mineralization process is complete after few days (Saleuddin and Wilbur, 1969). This contrasts with freshwater and marine species, for which a slow hole filling does not impair the vital functions of the animal, as long as the calcification compartment (extrapallial space) is isolated from the environment. This occurs by the mantle withdrawal around the lesion, followed by the tight sealing of the periphery of the hole by the mantle edge. For example, in the freshwater bivalve Anodonta grandis (Saleuddin, 1967), the formation of the organic membrane takes place after one day and the shell is fully re-mineralized after 6 months. In our case, the brown organic patch appears few days after lesion, fills the hole after 15 days in most cases, and the mineralization process is completed after 2 months in adult specimens. It is to note that the mineralization of the organic patch starts on the proximal side before the complete filling of the hole.

\subsection{Histology of the calcifying mantle}

One of the main histological finding of our study underlines the occurrence of granules, in the connective tissues of the mantle, but not in the epithelial cells. The presence of granules is clearly correlated to the repair process, since control animals do not exhibit granules in their connective tissues. Although our staining unambiguously demonstrates that these granules are calcium carbonate, we do not know yet which $\mathrm{CaCO}_{3}$ polymorph they are: amorphous (ACC), aragonite, calcite, vaterite. Previous studies have shown the existence of calcium storage granules in the mantle tissues of several molluscs (Istin, 1970; Roinel et al., 1973). One gives these granules two different locations: intracellular (Fournié and Chétail, 1982) or extracellular (interstitial) (Istin and Masoni, 1973). Recent findings suggest that several calcifying models, including sponges, sea urchins and molluscs, elaborate their crystalline skeleton via a transient amorphous phase (Weiss et al., 2002; Weiner et al., 2003; Addadi et al., 2006). In molluscs, the existence of ACC granules has been demonstrated (Simkiss, 1991). It is generally believed that ACC granules provide a rapidly available source of ionic calcium because they are more soluble than their crystalline counterpart.

The absence of granules in the epithelial cells calls for an explanation about the translocation of precursor mineral ions through the epithelial barrier to the repair zone. Two mechanisms may be inferred: a re-dissolution of the granules, followed by the transit of their constitutive ions in the epithelial cells and their extrusion in the extrapallial space; the direct migration of the granules through trans-epithelial channels (Sud et al., 2002). Our histological study does not permit to conclude which of these two mechanisms occurs.

Are hemocytes involved in the shell repair process of the green ormer? Let us recall that hemocytes (sometimes called amoebocytes), are free-circulating cells involved in immunological response and in wound healing (Armstrong et al., 1971). Their involvement in shell repair process has been reported a number of times. For example, in Pomacea paludosa amoebocytes are able to translocate into the extrapallial space following shell damage (Blackwelder and Watabe, 1977). However, this mechanism is not reported in Anodonta neither in Mytilus edulis (Saleuddin, 1967; Dunachie, 1963). In these two species, amoebocytes appear in the sub-epithelial region of the repairing mantle, suggesting their implication in the transport of mineral material. Recently, Mount and co-workers (2004) observed that hemocytes are involved in shell repair process (and maybe in 'normal' shell formation) of the Eastern oyster Crassostrea virginica by bringing and releasing single calcite crystals to the site of mineralization, where they can be remodelled and integrated to the shell mineralization. Our histological study does not allow observing such a phenomenon. However, it does not exclude the 
possibility that calcified granule-transporting hemocytes concentrate in the sub-epithelial connective tissues. Clearly, the identification of the calcium translocation pathway and the enumeration of cell types involved in calcium transport are important goals for the future studies.

\subsection{Diversity of shell microstructures}

The second major aspect to underline is the diversity of microstructures observed in the repair zone. This diversity affects the two dimensions of the patch: vertically, it is illustrated by a stratification of different microstructures. Horizontally, we observed modifications of the microstructures from the proximal to the distal zones. These lateral modifications are marked by the appearance/disappearance of layers, by the formation of lenticular layers, and by a general tendency to evolve to a more complex stratification from proximal to distal, the zone vertical to the distal border of the perforation exhibiting the most complex stratification. In normal Haliotis sp. shells, a great microstructural and mineralogical variability had been already observed, in the outer shell layer (Mutvei et al., 1985; Dauphin et al., 1989) whereas a proximal to distal variability of microstructures was more recently evidenced by Zaremba et al. (1996). In particular, Mutvei et al. (1985) showed the presence of islets of aragonite into the calcitic layer and the intimate association between different microstructures. In repaired shells, we observe a similar complexity, which leads to a true typology of 7 microstructures. Chronologically speaking, the $5 \mu \mathrm{m}$-thin blocklike layer is the first synthesized layer. Initially suspected to be calcitic by Zaremba et al. (1996), it was found later on to be aragonitic (Su et al., 2002). As suggested by Erasmus and co-workers (1994) and by Su et al. (2002), it may correspond to a layer secreted just after the stress due to the perforation. The fact that this layer is mostly present in the proximal zone reinforces this hypothesis, since the mantle retracts as soon as the perforation has been made. A second microstructure is composed of thin long prisms (2-3 $\mu \mathrm{m}$ diameter; length to diameter ratio $>10$ ), mostly observed in the distal zone of the repair. The sub-nacreous layer is a third type. Primarily defined by Uozumi and Suzuki (1981), the concept of sub-nacreous microstructure may be described in the present case as a texture where the single tablets are visible, although they tend to be smaller than normal tablets, and where the supracrystalline organization of these tablets is not columnar as in normal abalone nacre. We suggest that this type corresponds to immature nacre, the function of which is to rapidly fill some topographic irregularities, before the secretion of standard columnar nacre. The spherulitic microstructure (10-15 microns diameter) is another type, classical in Haliotidae (Mutvei et al., 1985). The aragonitic nature of spherulites has been demonstrated by Mutvei et al. (1985), Dauphin et al. (1989) and more recently, by Su et al., (2002). They are particularly well represented in the "accretionary mineralization" associated with upward bulge patches. Interestingly, in this zone, the transition between the spherulites and the nacre tablets is direct. From a molecular point of view, this suggests that the transition between these two microstructures may not require a drastic switch from a secretory repertoire to another one, but slight reorganization at the supramolecular level of similar macromolecules. Another microstructure of interest is the foliated-like structure, which is present as lenticular layers. This layer would resemble a nacre layer without lateral partitioning of the crystals (that define nacre microstructures), with the main difference that the laminations are thicker than nacre tablets. To our knowledge, this microstructure has not been described before in Haliotis tuberculata. The last microstructure observed is constituted by thick prisms, which make intermediary layers in nacre textures. These prisms are different from those described above in the distal part of the patch. Their lateral limits are in direct continuity with those of nacre columns. Here again, it is easily conceivable that the transition from one to the other type of microstructure does not require a complete change of secretory regime, but only minor readjustments. The most parsimonious hypothesis would suggest that columnar nacre is built by the horizontal partitioning of such prisms, or reversely, that prisms are made from the welding of superimposed nacre tablets. This old idea, expressed by Taylor (1973) for bivalves, would find a nice illustration with the present example.

The microstructural complexity of the repair patch results from two phenomena: the variations in the secretory regime during shell repair and the geometry of the calcifying mantle in contact with the repair zone. The variations in the secretory regime depend on the existence of a cellular zonation of the outer calcifying mantle. The identification of cellular types devoted to the secretion of a particular microstructure has been observed, in the pearl oyster (Sudo et al., 1997; Milet et al., 2004; Takeuchi and Endo, 2006) and in the green ormer (Sud et al., 2002; Jolly et al., 2004). In nacro-prismatic bivalves, cells responsible for the secretion of nacre are in dorsal position, in comparison to those involved in the secretion of prisms. In the case of shell repair in H. tuberculata, a similar situation is likely to occur and the nacre and sub-nacre tissues are probably synthesized by dorsal cells whereas the layer composed of minute prisms (seen in the distal part of the repair) are synthesized by cells 
which are close to the mantle edge. The second aspect concerns the geometry of the mantle tissues and the distance between the mineralizing tissues and the site of mineralization. From our experiments, a flat patch corresponds to the normal apposition of the mantle tissues to the site of the repair. An upward bulge occurs when the mantle tissues protrude from the perforation, i.e., from the organic patch layer. In that case, the protruding mantle tissues secrete the accretionary mineralization, whatever they are: the internal epithelial tissues or the tissues close to the periostracal ridge. The fact that the spherulitic accretionary mineralization is poorly organized suggests a lesser epithelial control, and maybe a distance between the epithelium and the site of mineralization. Obviously, the shell repair process in the green ormer requires a precise tracking with specific molecular markers, both in the epithelial tissues and in the mineralized repair patch.

\section{Acknowledgments}

The work of C. Fleury was financially supported by a CIFRE fellowship from the BiotechMarine company (Zone Industrielle - BP65, 22260 Pontrieux, France, www.biotechmarine.com). For the period 2003-2006, F. Marin benefited from an Aide Concertée Incitative Jeune Chercheur (ACl JC 3049). In 2007, F. Marin and G. Luquet are supported by a grant (ANR BLAN06-2_159971, ACCROEarth, coordinator G. Ramstein). F. Marin and C. Fleury thank Pascal Taubaty for the inclusion of the shell samples in Epoxy resin, Béatrice Adeline for her contribution in preparing the histological sections, and Alain Godon for his help in the conception of Figure 1.

\section{References}

Abolins-Krogis, A., 1958. The morphological and chemical characteristics of organic crystals in the regenerating shell of Helix pomatia L. Acta Zool. (Stockholm) 39, 19-38.

Abolins-Krogis, A., 1963a. The histochemistry of the mantle of Helix pomatia L. in relation to the repair of the damaged shell. Ark. Zool. 15, 461-474.

Abolins-Krogis, A., 1963b. On the protein stabilizing substances in the isolated b-granules and in the regenerating membranes of the shell of Helix pomatia L. Ark. Zool. 15, 475-484.

Abolins-Krogis, A., 1976. Ultrastructural study of the shell-repair membrane in the snail Helix pomatia L. Cell Tissue Res. 172, 455-476.

Abolins-Krogis, A., 1979. In vitro recalcification of the demineralized shell-repair membrane of the snail Helix pomatia L. Cell Tissue Res. 200, 487-494.

Addadi, L., Joester, D., Nudelman, F., Weiner, S. 2006. Mollusk shell formation: a source of new concepts for understanding biomineralization processes. Chemistry 12, 980-987.

Allaby, A., Allaby, M., 2003. Dictionary of Earth Sciences. Oxford University Press, New-York. Andrews, E. A., 1934. Shell repair by the snail Pleurodonte rostrata Pfr. Biol. Bull. 67, 294-299.

Armstrong, D.A., Armstrong, J.L., Krassner, S.M., Pauley, G.B., 1971. Experimental wound repair in the black abalone, Haliotis cracherodii. J. Invertebr. Pathol. 17, 216-227.

Beedham, G. E., 1965. Repair of the shell in species of Anodonta. Proc. Zool. Soc. London 145, 107125.

Blackwelder, P. L., Watabe, N., 1977. Studies on shell regeneration . II. The fine structure of normal and regenerated shell of the freshwater snail Pomacea paludosa. Biomineralization 9, 1-10.

Caseiro, J., Gauthier, J. P., 1997. L'huître aux lèvres noires, Pinctada margaritifera. I. Dommages causés sur le bord des valves - Reconstruction - Evaluation des paramètres de croissance de la nacre coquillière. Revue de Gemmologie A.F.G. 130, 7-13.

Caseiro, J., Gauthier, J. P., 1998. L'huître aux lèvres noires, Pinctada margaritifera. II. Altération créée par perçage central de la valve - Comparaison avec les altérations naturelles. Revue de Gemmologie, A.F.G. 133, 12-16.

Chan, W., Saleuddin, A. S. M., 1974. Evidence that Otala lactea (Müller) utilizes calcium from the shell. Proc. Malacol. Soc. London 41, 195-200.

Dauphin, Y., Cuif, J. P., Mutvei, H., Denis, A., 1989. Mineralogy, chemistry and ultrastructure of the external shell-layer in ten species of Haliotis with reference to Haliotis tuberculata (Mollusca: Archaeogastropoda). Bull. Geol. Inst. Univ. Uppsala 15, 8-17.

Davis, G. M., 1964. Shell regeneration in Oncomelania formosana. Malacologia 2, 145-158.

Dunachie, J. F., 1963. The periostracum of Mytilus edulis. Trans. Roy. Soc. Edinburgh 65, 383-410. 
Erasmus, J., Cook, P. A., Sweijd, N., 1994. Internal shell structure and growth lines in the shell of the abalone, Haliotis midae. J. Shellfish Res., 13, 493-501.

Fournié, J., Chétail, M., 1982. Accumulation calcique au niveau cellulaire chez les mollusques. Proceedings of the Seventh International Malacological Congress, Colloque Calcium et Structures Squelettiques. Malacologia 22, 265-284.

Gabe, 1968. Techniques histologiques. Editions Masson \& $C^{\mathrm{ie}}$. Paris.

Gabriel, J. M., 1981. Differing resistance of various mollusc shell materials to simulated whelk attack. J. Zool. 194, 363-369.

Ganagarajah, M., Saleuddin, A. S. M., 1972. Electron histochemistry of the outer mantle epithelium in Helix pomatia during shell regeneration. Proc. Malac. Soc. Lond. 40, 71-77.

Huchette, S., Paillard, C., Clavier, J., Day, R., 2006. Shell disease: abnormal conchiolin deposit in the abalone Haliotis tuberculata. Dis. Aquat. Org. 68, 267-271.

Istin, M., 1970. Rôle du manteau dans le métabolisme du calcium chez les lamellibranches. Bull. Inform. Sci. Techn. CEA 144, 53-80.

Istin, M., Masoni, A., 1973. Absorption et redistribution du calcium dans le manteau des lamellibranches en relation avec la structure. Calcif. Tiss. Res. 11, 151-162.

Jolly, C., Berland, S., Milet, C., Borzeix, S., Lopez, E., Doumenc, D., 2004. Zonal localization of shell matrix proteins in mantle of Haliotis tuberculata (Mollusca, Gastropoda). Mar. Biotechnol. 6, 541-551.

Kapur, S. P., Sen Gupta, A., 1970. The role of amoebocytes in the regeneration of shell in the land pulmonate, Euplecta indica (Pfieffer). Biol. Bull. 139, 502-509.

Lin, A., Meyer, M.A., 2005. Growth and structure in abalone shell. Mater. Sci. Engin. A 390, 27-41.

Loosanoff, V. L., Nomejko, C. A., 1955. Growth of oysters with damaged shell-edges. Biol. Bull. 108,151-159.

Marshall, D. J., Day, R., 2001. Change in the rate of shell deposition and shell microstructure in response to shell borers in the abalone Haliotis rubra. Mar. Freshw. Behav. Physiol. 34, 189-195.

Meenakshi, V. R., Blackwelder, P. L., Wilbur, K.M., 1973. An ultrastructural study of shell regeneration in Mytilus edulis (Mollusca: Bivalvia). J. Zool. 171, 475-484.

Meenakshi, V. R., Martin, A. W., Wilbur, K. M., 1974. Shell repair in Nautilus macromphalus. Mar. Biol. 27, 27-35.

Meenakshi, V. R., Blackwelder, P. L., Hare, P. E., Wilbur, K. M., Watabe, N., 1975. Studies on shell regeneration. I. Matrix and mineral composition of the normal and regenerated shell of Pomacea paludosa. Comp. Biochem. Physiol. A 50, 347-351.

Milet, C., Berland, S., Lamghari, M., Mouries, L., Jolly, C., Borzeix, S., Doumenc, D., Lopez, E., 2004. Conservation of signal molecules involved in biomineralisation control in calcifying matrices of bone and shell. C. R. Palevol. 3, 493-501.

Mount, A. S., Wheeler, A. P., Paradkar, R. P., Snider, D., 2004. Hemocyte-mediated shell mineralization in the eastern oyster. Science 304, 297-300.

Mutvei, H., Dauphin, Y., Cuif, J. P., 1985. Observations sur l'organisation de la couche externe du test des Haliotis (Gastropoda) : un cas exceptionnel de variabilité minéralogique et microstructurale. Bull. Mus. Natl. Hist. Nat. Paris, $4^{\mathrm{e}}$ sér., 7 sect. A, 73-91.

Muzii, E. O., Skinner, H. C., 1966. Calcite deposition during shell repair by the aragonite gastropod Murex fulvescens. Science 151, 201-203.

Nollens, H. H., Schofield, J. C., Keogh, J. A., Probert, P. K., 2002. Evaluation of radiography, ultrasonography and endoscopy for detection of shell lesions in live abalone Haliotis iris (Mollusca: Gastropoda). Dis. Aquat. Org. 50, 145-152.

Richardson, C. A., Runham, N. W., Crisp, D. J., 1981. A histological and ultrastructural study of the cells of the mantle edge of a marine bivalve, Cerastoderma edule. Tissue Cell. 13, 715-730.

Roinel, M., Morel, F., Istin, M., 1973. Etude des granules calcifiés du manteau des lamellibranches à l'aide de la microsonde électronique. Calc. Tiss. Res. 11, 163-170.

Saleuddin, A. S. M., 1967. The histochemistry of the mantle during the early stages of shell repair. Proc. Malacol. Soc. London 37, 371-380.

Saleuddin, A. S. M., Wilbur, K. M., 1969. Shell regeneration in Helix pomatia. Can. J. Zool. 47, 51-53.

Saleuddin, A. S. M., 1970. Electron microscopic study of the mantle of normal and regenerating Helix. Can. J. Zool. 48, 409-416.

Simkiss, K., Wilbur, K. M. 1989. Biomineralization. Cell Biology and Mineral Deposition. Academic Press, New York.

Simkiss, K., 1991. Amorphous minerals and theories of biomineralization. In "Mechanisms and Phylogeny of Mineralization in Biological Systems" (S. Suga and H. Nakahara, eds.), p 375-382. Springer-verlag, Tokyo. 
Su, X., Belcher, A. M., Zaremba, C. M., Morse, D. E., Stucky, G. D., Heuer, A. H. 2002. Structural and microstructural characterization of the growth lines and prismatic microarchitecture in red abalone shell and the microstructures of abalone "flat pearls". Chem. Mater. 14, 3106-3117.

Sud, D., Poncet, J. M., Saihi, A., Lebel, J. M., Doumenc, D., Boucaud-Camou, E. 2002. A cytological study of the mantle edge of Haliotis tuberculata L. (Mollusca, Gastropoda) in relation to shell structure. J Shellfish Res. 21, 201-210.

Sudo, S., Fujikawa, T., Nagakura, T., Ohkubo, T., Sakagushi, K., Tanaka, M., Nakashima, K., 1997. Structure of mollusc shell framework proteins. Nature 387, 563-564.

Takeuchi, T., Endo, K., 2005. Biphasic and dually coordinated expression of the genes encoding major shell matrix proteins in the pearl oyster Pinctada fucata. Mar. Biotechnol. 8, 52-61.

Taylor, J. D., 1973. The structural evolution of the bivalve shell. Palaeont. 16, 519-534.

Tsujii, T., 1976. An electron microscopic study of the mantle epithelial cells of Anodonta sp. during shell regeneration. In "The mechanisms of mineralization in the invertebrates and plants" (N. Watabe and K.M. Wilbur, eds), p 339-353. Univ. of South Carolina Press, Columbia.

Uozumi, S., Suzuki, S., 1979. "Organic membrane-shell" and initial calcification in shell regeneration. J. Fac. Sci. Hokkaido Univ., ser. IV, 19, 37-74.

Uozumi, S., Suzuki, S., 1981. The evolution of shell structures in the bivalvia. Study of Molluscan paleobiology. Prof M. Omori Memorial Volume, 63-77.

Wagge, L. E., 1951. The activity of amoebocytes and of alkaline phosphatases during the regeneration of the shell in the snail Helix aspersa. Q. J. Microsc.Sci. 92, 307-321.

Weiner, S., Levi-Kalisman, Y., Raz, S., Addadi, L., 2003. Biologically formed amorphous calcium carbonate. Connect. Tiss. Res. 44, 214-218.

Weiss, I. M., Tuross, N., Addadi, L., Weiner, S., 2002. Mollusc larval shell formation : amorphous calcium carbonate is a precursor phase. J. Exp. Zool. 293, 478-491.

Zaremba, C. M., Belcher, A. M., Fritz, M., Li, Y., Mann, S., Hansma, P. K., Morse, D. E., Speck, J. S., Stucky, G. D., 1996. Critical transitions in the biofabrication of abalone shells and flat pearls. Chem. Mater. 8, 679-690. 


\section{Figures}

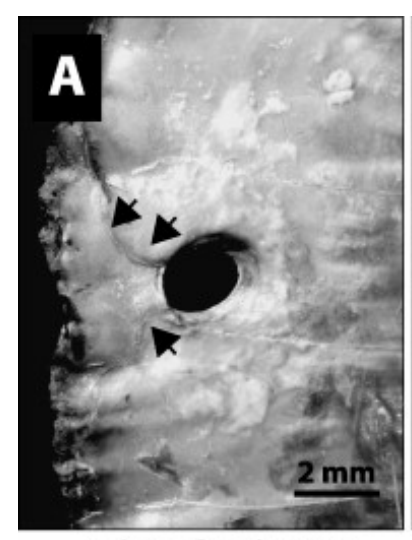

1 day after lesion

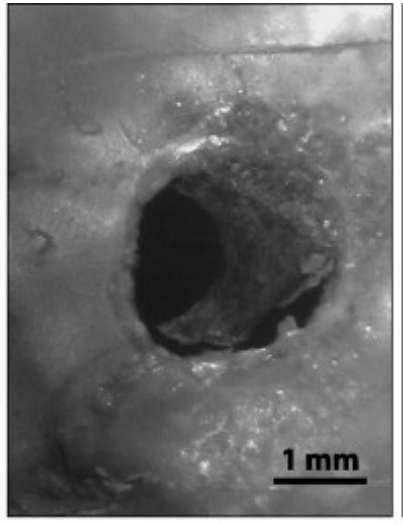

4 days

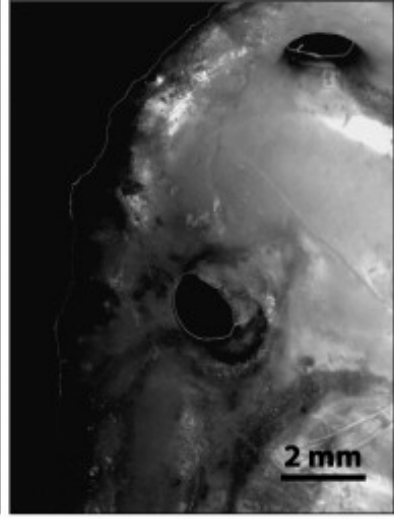

7 days

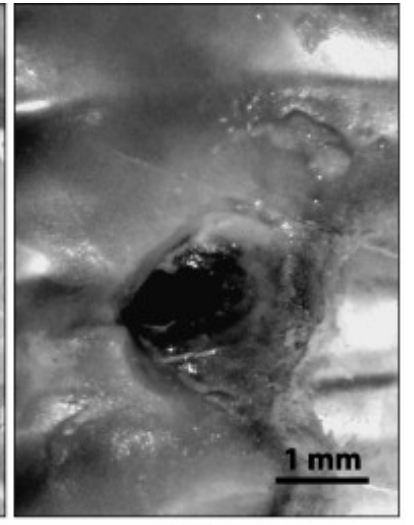

15 days

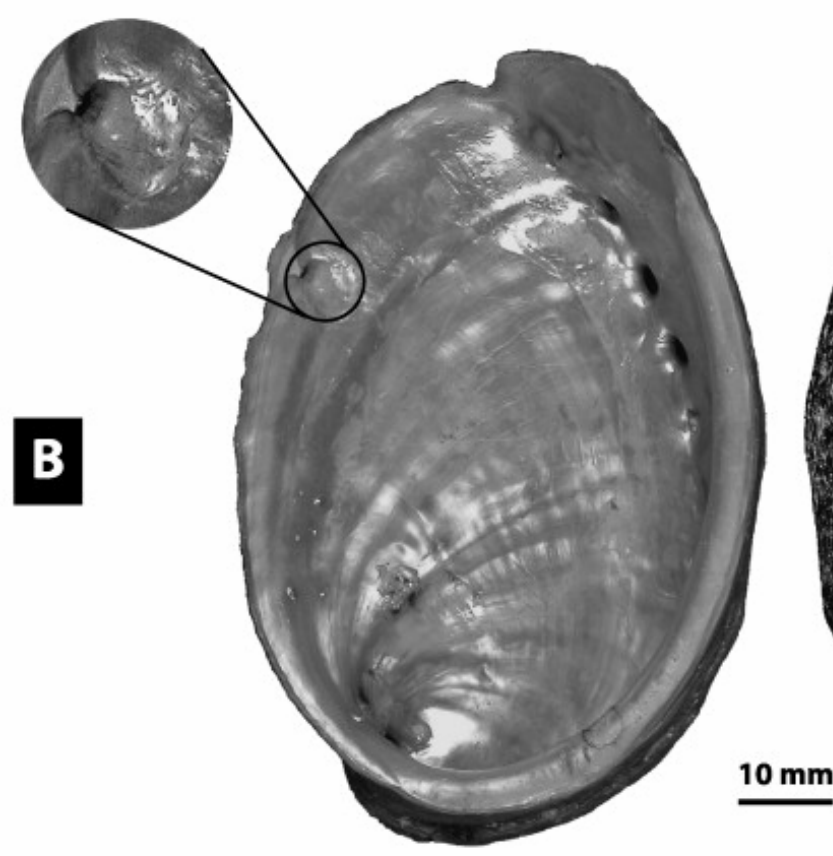

Internal side

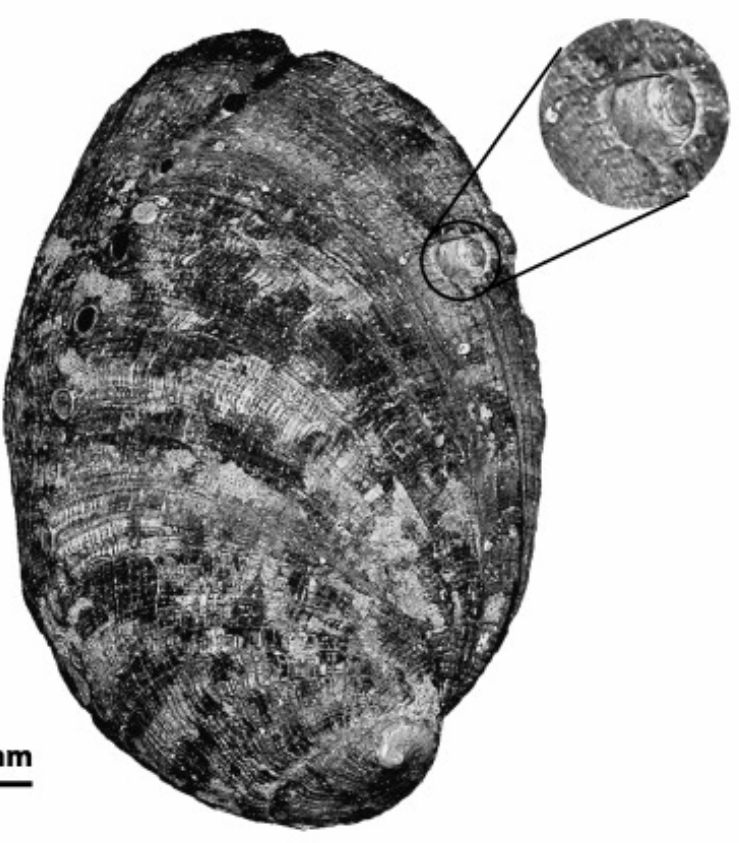

External side

c

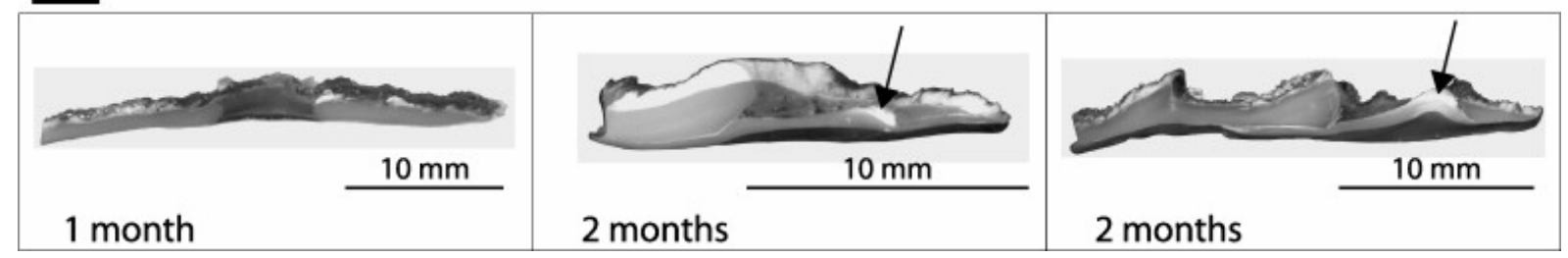

Figure 1. Shell repair kinetics at a macroscopic scale. A: steps of patch formation. One day after shell damage, we can observe the limits of organic matrix deposition (arrow heads). T4: A thin brown patch covers partially the hole. T7: The membrane covers one third of the hole and mineralisation of the membrane begins on the proximal edge. T15: the patch covers until two third of the hole. The patch is almost entirely mineralized. T1 and T7: same scale. T4 and T15: magnified twice in comparison to T1. $B$ : view of the internal and external sides of a fully repaired shell (60 days) and details of the repair patch. On the internal side of the shell the mineralization process is completed and the patch exhibits 
a nacreous appearance. Scale bar $=10 \mathrm{~mm}$. C: transverse shell sections in the zones of the repair patch after one month (left) and two months (middle and right). The white accretionary mineralizations (arrows) are clearly visible in the middle and right specimens. In the three cases, the proximal zone (with the shell apex) is on the left, and the shell edge, on the right.
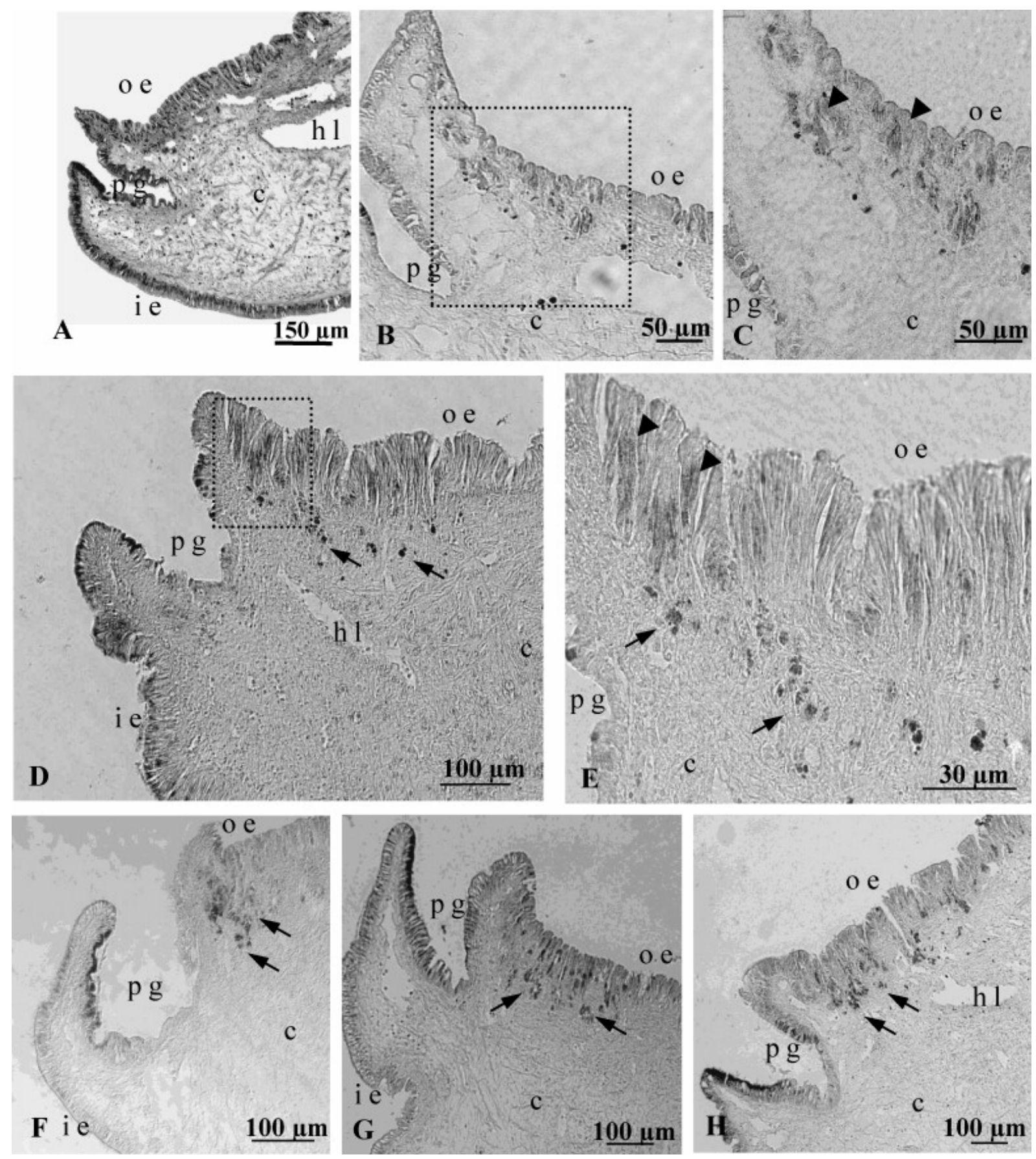

Figure 2. Histological study of the mantle of adult $H$. tuberculata during shell regeneration process. A: Trichrome staining of the mantle edge of $H$ tuberculata. Note the numerous cells into the connective tissue of the mantle. B to $\mathrm{H}$ : Von Kossa staining. $\mathrm{B}$ and $\mathrm{C}$ (enlargment of the boxed area in $\mathrm{B}$ ) Von Kossa staining few minutes after shell damaging (TO). A faint staining of the outer epithelium is seen (arrow heads). D: Von Kossa staining 4 days after shell lesion. Stained vesicles are observed in the connective tissue just under the repairing epithelium (arrows). The enlargement of the boxed zone in $E$ shows a faint staining of epithelial cells of the outer epithelium (arrow heads). F, G, H respectively 7 , 14 and 30 days after shell damage. In the three cases, $\mathrm{CaCO}_{3}$ containing vesicles are localized in the connective tissue (arrows). 
o e: outer epithelium, i e: inner epithelium, $\mathrm{p}$ g: periostracal groove, $\mathrm{h}$ l: hemolymphatic lacuna, c: connective tissue.
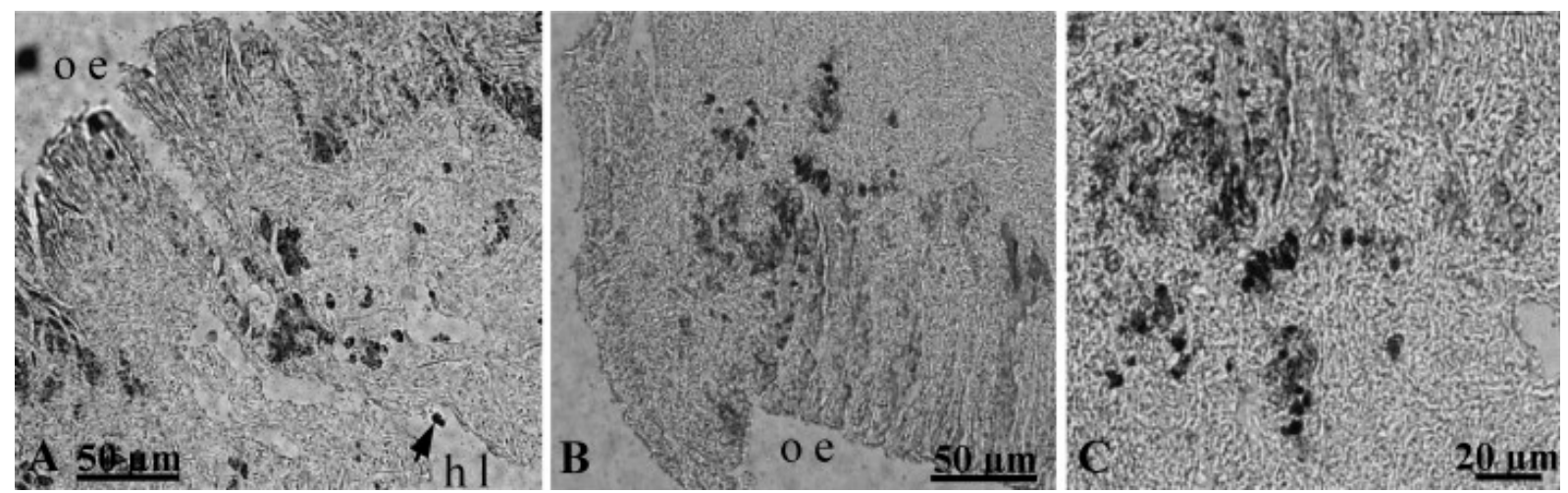

Figure 3. Observation of Von Kossa positive granules localized in the connective tissue. A and B: Stained $\mathrm{CaCO}_{3}$ vesicles at 7 and 30 days post lesion respectively. Vesicles are located beneath the outer epithelium in contact with lesion. In A, one vesicle is located in a hemolymphatic lacuna (arrow). C: Vesicles at 7 days. The vesicles have a rounded shape and their diameter is about $5 \mu \mathrm{m}$. 

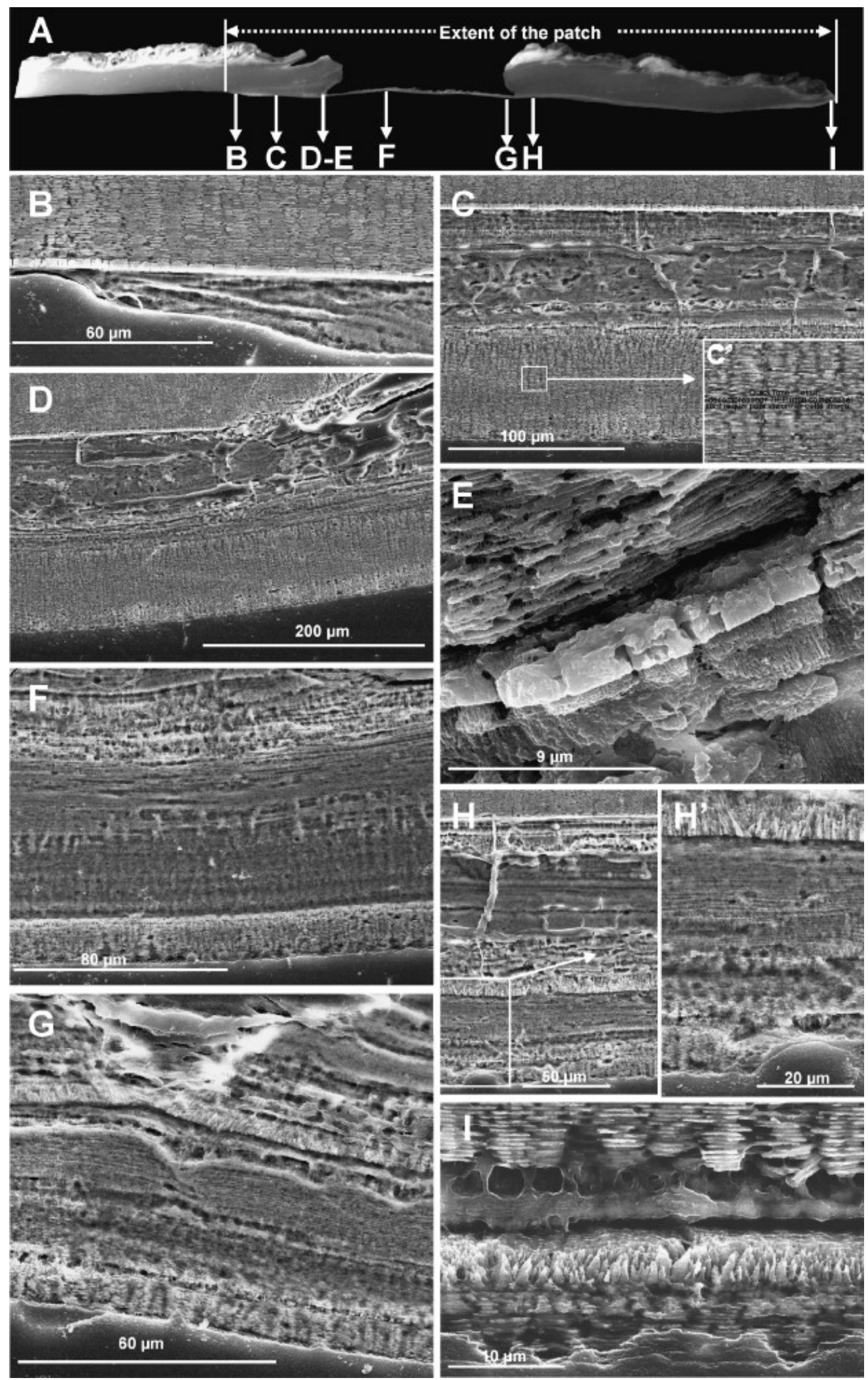

Figure 4. SEM observation of a shell repair, one month after the shell perforation. A: general view of the patch in cross section, from the proximal (left) to the distal (right) zone; the patch is still thin, although complete; the different observation zones are indicated by letters. B to I: different microstructures are observed along the repair. In B, C and E, note the thin blocklike layer, which appears white and segmented. In G, the repair zone is extremely stratified, with not less than 5 layers, respectively from top to bottom: organic, thin prisms, foliated-like, sub-nacreous and nacreous; the 
true nacre comprises only the bottom $10 \mu \mathrm{m}$, whereas it represents half of the thickness (around 70 $\mu \mathrm{m}$ ) of the patch in $\mathrm{C}$ for example.
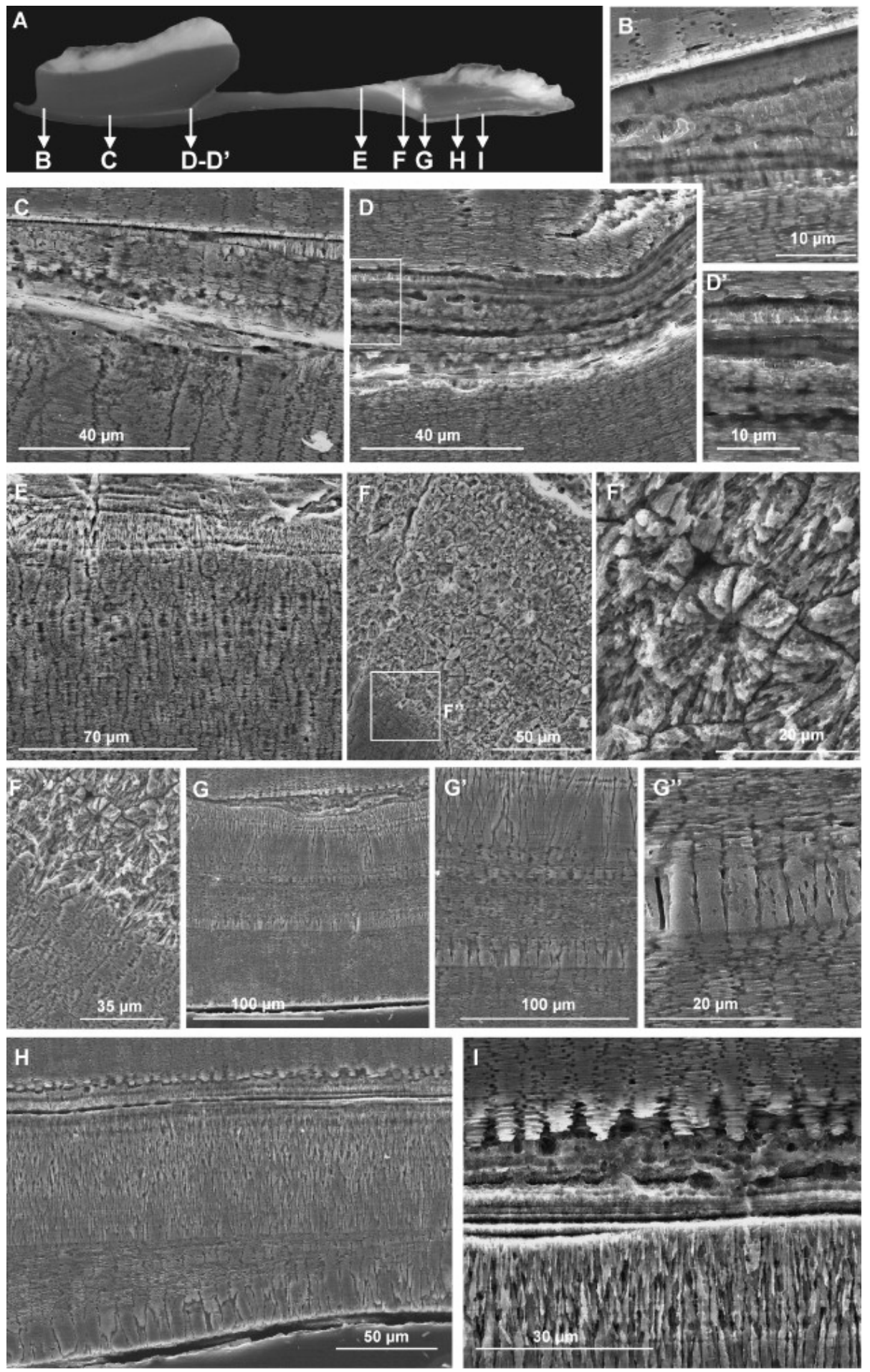

Figure 5. SEM observation of a shell repair, two months after the shell perforation. A: general view of the patch in cross section, from the proximal (left) to the distal (right) zone; the different observation zones are indicated by letters; Zone $\mathrm{F}$ corresponds to the accretionary white mineralization. $\mathrm{B}$ to I: different microstructures are observed along the repair. F, F' and F" represent the spherulitic microstructure. Note that the transition from spherulites to nacre tablets is direct, and that both exhibit similar diameters. G to G": alternating short prisms and nacre tablets, with direct transition from one to the other microstructure ( $G$ "). In the distal zones ( $\mathrm{H}$ and $\mathrm{I})$, thin prisms represent the dominant microstructure. 